\title{
INTRASPECIFIC AND INTERSPECIFIC PRE-ADULT COMPETITION \\ ON THE NEOTROPICAL REGION COLONIZER ZAPRIONUS \\ INDIANUS (DIPTERA: DROSOPHILIDAE) UNDER \\ LABORATORY CONDITIONS ${ }^{(1)}$
}

\author{
LUÍS GUSTAVO DA CONCEIÇÃO GALEGO ${ }^{(2)}$; CLAUDIA MARCIA APARECIDA CARARETO ${ }^{(2)}$
}

\begin{abstract}
This study analyzes the pre-adult interactions of Zaprionus indianus, a recently-introduced species in Brazil, with two others Drosophilidae under laboratory conditions. The effects of larval residues on the viability and on the developmental time of Z. indianus, Drosophila simulans and D. sturtevanti were used to evaluate pre-adult competitive interactions, conditioning the culture medium with larval residues. Pre-adult interactions between $Z$. indianus, D. sturtevanti and D. simulans may affect their relative abundance over time, since the viability of Z. indianus was negatively affected by residues of $D$. sturtevanti, and its residues reduced the viability of $D$. simulans and the developmental time of both $D$. simulans and D. sturtevanti.
\end{abstract}

Key words: Zaprionus indianus; fitness components; competitive interactions; viability; developmental time.

\section{RESUMO}

\section{COMPETIÇÃO PRÉ-ADULTA INTRA E INTERESPECÍFICA, EM ZAPRIONUS INDIANUS (DIPTERA: DROSOPHILIDAE), ESPÉCIE COLONIZADORA DA REGIÃO NEOTROPICAL, SOB CONDIÇÕES LABORATORIAIS}

Este estudo é uma análise das interações pré-adultas, sob condições laboratoriais, da mosca-dofigo Zaprionus indianus, espécie recentemente introduzida no Brasil, com dois outros drosofilídeos. A interferência de meio de cultura, acrescido de resíduos larvais, sobre a viabilidade e o tempo de desenvolvimento de Z. indianus, Drosophila simulans e D. sturtevanti foi utilizada para avaliar as interações competitivas pré-adultas. As interações pré-adultas entre Z. indianus, D. sturtevanti e D. simulans podem afetar sua abundância relativa ao longo do tempo, pois a viabilidade de Z. indianus foi negativamente afetada por resíduos de D. sturtevanti; os resíduos da mosca-do-figo reduziram a viabilidade de $D$. simulans e o tempo de desenvolvimento tanto de D. simulans como de D. sturtevanti.

Palavras-chave: Zaprionus indianus; valor adaptativo; interações competitivas; viabilidade; tempo de desenvolvimento.

$\left({ }^{1}\right)$ Received for publication in May 25, 2004 and accepted in March 14, 2005.

$\left(^{2}\right)$ Departamento de Biologia, IBILCE, Universidade Estadual Paulista, Rua Cristóvão Colombo, 2.265, 15054-000 São José do Rio Preto (SP), Brasil. E-mail: carareto@ibilce.unesp.br 


\section{INTRODUCTION}

Zaprionus indianus is a Drosophilidae species that was recently introduced into the Neotropical region. The first published record refers to individuals observed on fallen persimmon fruits (Diospyrus kaki L.; Ebenaceae) in the São Paulo metropolitan area, São Paulo state, Brazil (VILELA, 1999). In the same year, a large number of $Z$. indianus were found feeding on and ovipositing in figs (Ficus carica L.; Moraceae) making them inappropriate for human consumption and occasioning the loss of approximately $50 \%$ of that crop. So, this African insect may now be reaching pest status in the main fig growing area in the state of São Paulo (VILELA et al., 2001).

According to Mack and D'Antonio (1998), species removed from or added to an environment which strongly interact with native species frequently produce ecosystem structure alterations and offer model systems for understanding the mechanisms by which species alter disturbance regimes. These alterations occur in both disrupted and intact systems, resulting in profound changes in many cases, including changes in ecosystem processes that ultimately control plant and animal activities and direct species replacements (KNops et al., 1999).

Mixing cultures makes it possible to study different parameters as a mean of evaluating the performance of one species when in the presence of another. Of diverse possible parameters, developmental time and viability are most frequently analyzed in studies that involve competition (GonZÁles-CANDElas et al., 1990). Ohba (1961) noticed diverse consequences of competition in species of Drosophila, such as increases in the variation of the duration of the pre-adult period, decreases in larval viability, increases in variation of the flies' body size, and decreases in pupal viability.

In Drosophilidae, developmental time and eggadult viability are modified when the development occurs in a culture medium previously used by larvae of the same or different species (WEISBRot, 1966; DawOod and StrickBerger, 1969; HuAng et al., 1971; BudNiK and BrNCIC, 1975; 1983; Hemmat and EgGLESTON, 1988; BuDNIK et al., 2001). BuDNIK et al. (2001) demonstrated that competitive interactions between pre-adult individuals of different species can be established, with deterioration or facilitation of the viability of one or both species.

These effects may be due to the restriction of nutrition resources or even of substratum contamination by metabolic residues during the larval development.
Larval population density is also an important competitive factor. In Drosophila species, population agregation of some species generally leads to individual body size decrease, developmental time increase and fecundity decrease (Mitrofanov and BRODSKAYA, 1976; SCHEIRING et al., 1984; BRNCIC, 1987). Similar results were obtained by Amoudi et al. (1993) in experimental populations with different initial densities of $Z$. indianus larvae. The authors observed that the bigger the $Z$. indianus population size, the greater is the larva-adult developmental time and the lesser are the survival rates and adult body sizes. These authors concluded that, under intraspecific competition, the alterations in the developmental time, survival and body size would be related to the depletion of resources and the increase in larval residues, such as uric acid and $\mathrm{CO}_{2}$.

Z. indianus is a species that has shown a great spread in the Neotropical region (Tidon et al., 2003) and information about its interactions with native Drosophilidae is unavailable. Aiming to evaluate the nature of these interactions, we studied the impact on viability and developmental time of metabolic waste products of two species of the genus Drosophila that occur at high abundances in the same area as $Z$. indianus during our collections, D. sturtevanti and D. simulans.

\section{MATERIAL AND METHODS}

Drosophilids were collected in orchard with different fruit trees in Mirassol, São Paulo State, Brazil $\left(49^{\circ} 30^{\prime} \mathrm{W}, 20^{\circ} 47^{\prime} \mathrm{S}\right)$. Five traps with fermented banana were used, placed $1.5 \mathrm{~m}$ from the ground. The collections were made in the rainy (October, 2001 and January, 2002) and dry (April and June, 2002) seasons. The most abundant species of Drosophila in the rainy season was $D$. sturtevanti (saltans group), a native Neotropical species, and in the dry season was $D$. simulans (melanogaster group), an introduced species. The flies of these three species obtained in the collections were separated and maintained in $250 \mathrm{ml}$ bottles with banana-agar culture medium and the larvae yielded were used in pre-adult competition studies.

The method employed to investigate the effects of metabolic waste products of imature stages on development of species that share the same environment was similar to that used by BUDNIK and BRNCIC (1975). According to this method, larvae of the same (to evaluated intraspecific competition) or 
different (to evaluated interspecific competition) species are transferred to vials with fresh food and maintained there during a certain period of time for releasing metabolic residues in the culture medium. Afterwards, the vials are frozen in order to kill the larvae. These vials containing culture medium with the metabolic waste products and the dead bodies of the larvae are named as "conditioned" with compounds of a particular species. The next step is the transfer of living larvae of a species to be tested into the conditioned vials. This approach can show whether the residues of a particular species can affect its own or the other species development by evaluating fitness components of such species.

In this study, three types of competition were evaluate: (1) intraspecific competition: the medium was conditioned with residues of the same species to be tested (for example, larvae of $Z$. indianus placed in vials conditioned with residues of $Z$. indianus); (2) interspecific competition: the medium was conditioned with residues of a different species (for example, larvae of $Z$. indianus placed in vials conditioned with $D$. simulans) and, (3) intra and interspecific competition: the medium was conditioned with residues of the species to be tested plus residues of a different species (for example, larvae of $Z$. indianus placed in vials conditioned with $Z$. indianus and of $D$. simulans).

The viability and developmental time of the species to be tested (ST) were studied in vials containing $5 \mathrm{ml}$ of banana-agar medium, replicated 10 times: Z. indianus (ST1: zp), D. sturtevanti (ST2: st) and D. simulans (ST3: sm). Vial 1 was nonconditioned (Vnc) and the vials 2 to 4 were conditioned each one with 30 larvae one-day-old: vial 2 was conditioned with intraspecific residues (Vzp, Vst or Vsm), vial 3 with interspecific residues (Vzp, Vst or Vsm) and vial 4 was conditioned with intra and interspecific residues using 15 larvae of each species (Vzp+st or $\mathrm{V} z p+s m)$. For example, ST1Vnc means that the $Z$. indianus viability or developmental time was recorded in nonconditioned medium; ST2Vzp means that the $D$. sturtevanti viability or developmental time was recorded in medium conditioned with residues of $Z$. indianus as well as ST3Vzp+sm means that these parameters of $D$. simulans was recorded in medium conditoned with larvae of $Z$. indianus plus $D$. simulans. These vials were maintained in a constant temperature chamber at $25^{\circ} \mathrm{C}$ during five days to allow the larvae to develop and to release the metabolic waste products. Thereafter, they were frozen at -20 ${ }^{\circ} \mathrm{C}$ for about $24 \mathrm{~h}$ in order to kill the larvae. After the vials were thawed at $25^{\circ} \mathrm{C}, 20$ one-day-old larvae of the species to be tested were transferred to each vial and their viability and developmental time were recorded.

ANOVA and Tukey's test for pairwise comparisons (significance level at $\alpha=0.05$ ) were used to compare the mean viability and developmental time of each species and between species in different conditioned mediums of culture.

\section{RESULTS}

The viability and the larva to adult developmental time were used to evaluate the effects of the larval competitive interactions between $Z$. indianus and the Drosophila species. Z. indianus viability ranged from $50.0 \%$ in intra and interspecific (D. sturtevanti) residues to $70.0 \%$ in intraspecific residues $(P<0.01)$ and its developmental time ranged from 19.06 to 20.24 days in interspecific residues of $D$. simulans and $D$. sturtevanti $(P>0.05)$, respectively. The variation of $D$. sturtevanti viability on the presence of $Z$. indianus residues was also not significant. However, the variation of the mean developmental time of $D$. sturtevanti on the presence of $Z$. indianus residues was highly significant $(P<0.001)$, the smallest value was observed in interspecific residues of $Z$. indianus (18.91 days) and the greatest in the non-conditioned medium $(21.86$ days). D. simulans viability $(P<0.01)$ ranged from $55.0 \%$ in the presence of $Z$. indianus residues to $74.5 \%$ in the presence of intraspecific and interspecific (Z. indianus) residues; its developmental time $(P<0.01)$ varied from 10.91 days in intra and interspecific residues ( $Z$. indianus) to 11.51 days in the non-conditioned medium. Table 1 presents the averages and the standard-errors, as well as the F-values for homogeneity of means of viability and developmental time of each species in different types of conditioning.

The pairwise comparisons between the conditioning types and control inside each experimental group show that the residues of $D$. sturtevanti affect significantly the viability of $Z$. indianus as wel as the residues of $Z$. indianus affect the viability of $D$. simulans. The viability of $Z$. indianus in non-conditioned vials $(67 \%)$ and in vails conditioned with its own residues $(70 \%)$ is significantly reduced in vials conditioned with residues of $D$. sturtevanti $(57.5 \%)$ or of $D$. sturtevanti plus Z. indianus (50\%) (Table 1$)$. Also, the viability of $D$. simulans in non-conditioned vials $(70 \%)$ is reduced by the Z. indianus residues (55\%). 
On the other hand, the developmental time of $Z$. indianus was not significantly affected by any residues, but its residues affected significantly this fitness component of $D$. sturtevanti and $D$. simulans.

The developmental time of $D$. sturtevanti, in vials non-conditioned (21.86 days) was reduced when compared to vails conditioned with larvae of $Z$. indianus (19.97 days) or of Z. indianus plus D. sturtevanti (20.87 days) as well as was reduced in $D$. simulans developed in non-conditioned vails (11.51 days), in vials conditioned with $Z$. indianus (11.10 days) or with the $Z$. indianus plus the $D$. simulans (10.91) residues. It can be also seen that the metabolic residues of $D$. sturtevanti or $D$. simulans reduce its own developmental times (Tables 1 and 2).

Table 1. Means and standard-errors for larva-adult viability (\%) and developmental time (days) of Zaprionus indianus (zp), Drosophila sturtevanti (st) and D. simulans ( $\mathrm{sm}$ ) in non-conditioned and conditioned media (ST: species to be tested; V: vial with conditioned medium).

\begin{tabular}{|c|c|c|c|}
\hline Species tested & Conditioned vial & Viability $($ Mean \pm SE) & Developmental time (Mean \pm SE) \\
\hline Z. indianus & Vnc & $67.0 \pm 2.9$ & $19.61 \pm 0.37$ \\
\hline \multirow[t]{6}{*}{ ST1 } & $\mathrm{V} z p$ & $70.0 \pm 3.2$ & $19.76 \pm 0.24$ \\
\hline & Vst & $57.5 \pm 3.0$ & $20.24 \pm 0.32$ \\
\hline & Vsm & $64.0 \pm 3.8$ & $19.06 \pm 0.21$ \\
\hline & $\mathrm{V} z p+s t$ & $50.0 \pm 2.4$ & $19.50 \pm 0.21$ \\
\hline & $\mathrm{V} z p+s m$ & $59.5 \pm 2.2$ & $19.53 \pm 0.22$ \\
\hline & $\mathrm{F}_{6 ; 54}$ & $7.77^{* *}$ & 2.04 \\
\hline D. sturtevanti & $\mathrm{V} n \mathrm{c}$ & $87.5 \pm 2.4$ & $21.86 \pm 0.32$ \\
\hline \multirow[t]{4}{*}{ ST2 } & Vst & $76.0 \pm 4.5$ & $18.91 \pm 0.34$ \\
\hline & Vzp & $73.0 \pm 4.7$ & $19.97 \pm 0.37$ \\
\hline & $\mathrm{V} z p+s t$ & $84.0 \pm 3.7$ & $20.80 \pm 0.32$ \\
\hline & $\mathrm{F}_{3 ; 36}$ & 2.71 & $13.66^{* * *}$ \\
\hline D. simulans & Vnc & $70.0 \pm 4.5$ & $11.51 \pm 0.11$ \\
\hline \multirow[t]{8}{*}{ ST3 } & Vsm & $67.0 \pm 3.6$ & $11.04 \pm 0.06$ \\
\hline & $\mathrm{Vzp}$ & $55.0 \pm 4.1$ & $11.10 \pm 0.10$ \\
\hline & $\mathrm{V} z p+s m$ & $74.5 \pm 2.0$ & $10.91 \pm 0.04$ \\
\hline & $\mathrm{F}_{3 ; 36}$ & $5.06^{* *}$ & $9.72^{* * *}$ \\
\hline & $\mathrm{nc}$ & $\mathrm{F}_{2 ; 27}: 17.80^{* * *}$ & $F_{1 ; 18}: 13.46^{* * *}$ \\
\hline & intra & $\mathrm{F}_{2 ; 27}: 01.72^{* * *}$ & $F_{1 ; 18}: 03.06^{* * *}$ \\
\hline & inter (st and $s m)$ & $F_{3 ; 36}: 07.76^{* * *}$ & $\mathrm{~F}_{2 ; 27}: 04.07^{* * *}$ \\
\hline & intra and inter $(\mathrm{zp}+\mathrm{st}$ and $z p+s m)$ & $\mathrm{F}_{3 ; 36}: 15.41^{* * *}$ & $\mathrm{~F}_{2 ; 27}: 08.46^{* * *}$ \\
\hline
\end{tabular}

${ }^{*} \mathrm{p}<0.05 ;{ }^{* *} \mathrm{p}<0.01 ;{ }^{* * *} \mathrm{p}<0.001$

nc: non-conditioned medium

inter: interspecific residues. $\mathrm{i}$

intra: intraspecific residues.

intra + inter: intra and interspecific residues. 
Table 2. Pairwise comparisons of conditioning type effects on viability and developmental time in Zaprionus indianus ( $z p$ ), Drosophila sturtevanti (st) and D. simulans ( $\mathrm{sm}$ ). (nc: non-conditioned; ST: species to be tested; V: vial with conditioned medium)

\begin{tabular}{|c|c|c|c|}
\hline $\begin{array}{l}\text { Species tested/ } \\
\text { Conditioning type }\end{array}$ & Conditioning type & Viability & Developmental time \\
\hline \multicolumn{4}{|l|}{ Z. indianus (ST1) } \\
\hline \multirow[t]{5}{*}{ Vnc } & $\mathrm{V} z p$ & NS & NS \\
\hline & Vst & * & NS \\
\hline & $\mathrm{V} z p+s t$ & NS & NS \\
\hline & $\mathrm{Vsm}$ & NS & NS \\
\hline & $\mathrm{V} z p+s m$ & NS & NS \\
\hline \multirow[t]{4}{*}{$\mathrm{V} z p$} & Vst & $*$ & NS \\
\hline & $\mathrm{V} z p+s t$ & * & NS \\
\hline & Vsm & NS & NS \\
\hline & $\mathrm{V} z p+s m$ & NS & NS \\
\hline \multirow[t]{3}{*}{ Vst } & $\mathrm{V} z p+s t$ & NS & NS \\
\hline & $\mathrm{V} z p+s m$ & NS & NS \\
\hline & Vsm & NS & NS \\
\hline \multirow[t]{2}{*}{$\mathrm{V} z p+s t$} & $\mathrm{~V} z p+s m$ & NS & NS \\
\hline & Vsm & NS & NS \\
\hline Vsm & $\mathrm{V} z p+s m$ & NS & NS \\
\hline \multicolumn{4}{|l|}{ D. sturtevanti (ST2) } \\
\hline \multirow[t]{3}{*}{ Vnc } & Vst & NS & * \\
\hline & $\mathrm{V} z p$ & NS & * \\
\hline & $\mathrm{V} z p+s t$ & NS & * \\
\hline \multirow[t]{2}{*}{ Vst } & $\mathrm{V} z p$ & NS & NS \\
\hline & $\mathrm{V} z p+s t$ & NS & $*$ \\
\hline $\mathrm{V} z p$ & $\mathrm{~V} z p+s t$ & NS & NS \\
\hline \multicolumn{4}{|l|}{ D. simulans (ST3) } \\
\hline \multirow[t]{3}{*}{ Vnc } & Vsm & NS & * \\
\hline & $\mathrm{V} z p$ & $*$ & * \\
\hline & $\mathrm{V} z p+s m$ & NS & * \\
\hline \multirow[t]{2}{*}{ Vsm } & $\mathrm{V} z p$ & NS & NS \\
\hline & $\mathrm{V} z p+s m$ & NS & NS \\
\hline $\mathrm{V} z p$ & $\mathrm{~V} z p+s m$ & $*$ & NS \\
\hline
\end{tabular}

NS: non-significant. ${ }^{*} \mathrm{p}<0.05$.

\section{DISCUSSION}

Competition can occurr in Drosophilidae pre-adult stages due to high larval density and depletion of resources (Amoudi et al., 1993), or due to larval residues produced by individuals in the medium which can interact with the metabolism of larvae (BUdNIK and Cifuentes, 1995; BUDNIK et al., 2001).

These residues would intervene or promote the growth of yeast or other resources necessary for the survival and the development of these Drosophilidae, reducing or facilitating their development (WеіsвRот, 1966).

We exposed larvae of $Z$. indianus to residues of $D$. sturtevanti and $D$. simulans, species that we had observed to occur at high frequencies in the same area
(Mirassol, State of São Paulo) as Z. indianus; the first during the rainy season and the second during the dry season. The pairwise comparison showed that the developmental time of $Z$. indianus was not affected by any type of competitor residues, however, its viability was reduced. Individuals of $Z$. indianus exposed to the non-conditioned medium and to that with intraspecific residues presented practically the same viability (67\% and $70 \%$, respectively). However, its viability was significantly reduced when developed in medium conditioned with residues of $D$. sturtevanti: a reduction of $14.9 \%$ comparing $Z$. indianus developed in non-conditioned medium versus in medium conditioned only with residues of $D$. sturtevanti; and $17.9 \%$ and $28.6 \%$, respectively, when comparing the viability of $Z$. indianus which was developed in medium conditioned with its own residues versus in medium conditioned only with $D$. sturtevanti or with its own residues plus those of $D$. sturtevanti. 
These results indicate a possible deleterious effect of $D$. sturtevanti on Z. indianus survival. On the contrary, it can be seen that $Z$. indianus residues reduced significantly the viability of $D$. simulans $(21.4 \%)$ as shown by the viability of $D$. simulans in non-conditioned medium versus that in environment conditioned with $Z$. indianus residues.

Neither type of conditioned medium significantly affected the viability of $D$. sturtevanti; however, the developmental time of this species was affected by residues of $Z$. indianus. A higher developmental speed is suggested by the pairwise comparisons of the developmental time of this species in non-conditioned medium and the values in medium conditioned only with $\mathrm{Z}$. indianus (a reduction of $8.6 \%$ ) or with its own residues plus those of $Z$. indianus (a reduction of $4.8 \%$ ). Although some exceptions can be observed, these comparisons suggest a possible facilitator role of the $Z$. indianus larval residues on the $D$. sturtevanti development. Despite the lower degree, a similar phenomenon was observed in $D$. simulans development that was significantly reduced in the presence of $Z$. indianus $(3.6 \%)$ or when exposed to the $Z$. indianus plus the $D$. simulans (5.2 $\%)$ larval residues.

BUDNIK et al. (2001) pointed out that larval residues may not only be associated with the factors that reduce viability and increase developmental time but may also act as a facilitator of development. For example, pre-adult viability is increased when $D$. willistoni and $D$. simulans grow in a culture medium with residues of their own species (BUDNIK and BRNCIC, 1976), but in D. pavani, viability was reduced when exposed to larval intraspecific residues (BUDNIK, 1977). BudNiK and Cifuentes (1995) found different viability patterns and developmental times in intraspecific competition studies involving $D$. pseudoobscura from different geographic regions. The authors concluded that each geographic population has its own genetic background as a response to the history of interactions between species that inhabit the same geographic region.

Our results suggest that the interaction between pre-adult stages of $Z$. indianus, $D$. sturtevanti and $D$. simulans in oviposition sites can affect their relative abundance over time. Possible results are the elimination of one or more of these competitor species or coexistence among them, as occurred with other invading Drosophilidae species, such as $D$. malerkotliana and D. simulans, which reached equilibrium with native Neotropical populations, after a population demographic explosion of these species. Monitoring the interactions among Z. indianus and other Drosophilidae species over time will be important to evaluate the evolutionary dynamics and impact of this species on the Neotropical environment.

\section{ACKNOWLEDGEMENTS}

This work was supported by FAPESP grants and a CAPES fellowship to L.G.C.G. We thank A.J. Manzato for statistical advice and P. J. Harris for reviewing the English text.

\section{REFERENCES}

AMOUD, M.A.; DIAB, F.M.; ABOU-FANNAH, S.S.M. Effects of larval population density on the life cycle parameters in Zaprionus indianus Gupta (Diptera: Drosophilidae). Pakistan Journal of Zoology, v. 25, p. 37-40, 1993.

BRNCIC, D. Coexistencia de diferentes especies de Drosophila en frutas fermentadas naturalmente. Médio Ambiente,Casilla, v.8, p. 3-9, 1987.

BUDNIK, M. The inhibition of Drosophila pavani preadult viability by different concentrations of larval biotic residues. Ciência e Cultura, São Paulo, v.29, 675-676, 1977.

BUDNIK, M.; BRNCIC, D. Preadult competition between Drosophila pavani and D. melanogaster, D. simulans and D. wilistoni. Ecology, Brooklyn, v. 55: p. 657-661, 1975.

BUDNIK, M.; BRNCIC, D. Effects of larval biotic residues on viability in four species of Drosophila. Evolution, Lancaster, v. 29: p. 777-780, 1976.

BUDNIK, M.; CIFUENTES, L. Further studies of preadult competition between European and Chilean stocks of Drosophila subobscura and the Chilean species Drosophila pavani. Evolución Biological, Bogota, v.8/9, p.37-47, 1995.

BUDNIK, M.; VALENTE, V.L.; MANRIQUEZ, G.; CIFUENTES, L. Preadult interactions between Drosophila simulans and D.willistoni (Diptera: Drosophilidae) emerged from the same substrata. Acta Entomologica Chilena, Santiago de Chile, v. 25: p. 21-6, 2001.

DAWOOD, M.M.; STRICKBERGER, M.W. The effect of larval interaction on viability in Drosophila melanogaster. Genetics, Pittsburg, v. 63: p. 201-211, 1969.

GONZALES-CANDELAS, F.; MENSUA, J.L.; MOYA, A. Larval competition in Drosophila melanogaster: effects on developmental time. Genetica, Dordrecht, v. 82: p.33-44, 1990.

HEMMAT, M.; EGGLESTON, P. Competitive interactions in Drosophila melanogaster: genetic variation for interference through media conditioning. Heredity, Edinburgh, v.61, p.347$354,1988$. 
HUANG, S.L.; SINGH, M.; KOJIMA, K. A study of frequency dependent selection observed in the esterase-6 locus of Drosophila melanogaster using a conditioned media method. Genetics, Pittsburgh, v. 68: p. 97-104, 1971.

KNOPS, J.M.H.; TILMAN, D.; HADDAD, N.M.; NAEEM, S.; MITCHELL, C.E.; HAARSTAD, J.; RITCHIE, M.E.; HOWE, K.M.; REICH, P.B.; SIEMANN, E.; GROTH, J. Effects of plant species richness on invasion dynamics, disease outbreaks insect abundances and diversity. Ecology Letters, Oxford, v.2, p.286-293, 1999.

MACK, M.C.; D'ANTONIO, C.M. Impact of biological invasion on disturbance regimes. Trends in Ecology and Evolution, Cambridge, v.13, p.195-198, 1998.

MITROFANOV, V.G.; BRODSKAYA, T.V. Influence of the temperature and population density of the larvae on the appearance of mutations in Drosophila virilis. Genetika, Moscow, v. 11, p. 1244-1247, 1976.

OHBA, S. Analytical studies on the experimental population of Drosophila. 1.The effect of larval population density upon the pre-adult growth in $D$. melanogaster and $D$. virilis with special reference to their nutritional conditions. Biology Journal of Okayama University, Okayama, v.7, p.87-125, 1961.
SCHEIRING, J.F.; DAVIS, D.G.; RANASINGHE, A.; TEARE, C.A. Effects of larval crowding on life history parameters in Drosophila melanogaster Meigen (Diptera: Drosophilidae). Annal of Entomological Society of America, Washington, v.77, p.329332, 1984.

TIDON, R.; LEITE, D.F.; LEÃO, B.F.D. Impact of the colonisation of Zaprionus (Diptera, Drosophilidae) in different ecosystems of the Neotropical Region: 2 years after the invasion. Biological Conservation, Barking, v.12, p.299-305, 2003.

VILELA, C.R. Is Zaprionus indianus Gupta, 1970 (Diptera, Drosophilidae) currently colonizing the Neotropical region? Drosophila Information Service, Norman, v.82, p.37-39, 1999.

VILELA, C.R.; TEIXEIRA, E.P.; STEIN, C.P. Mosca-africana-dofigo, Zaprionus indianus (Diptera: Drosophilidae). In: HISTÓRICO e impacto das pragas introduzidas no Brasil. Ribeirão Preto: Holos, 2001. p.48-52.

WEISBROT, D.R. Genotypic interactions among competing strains and species of Drosophila. Genetics, Pittsburg, v.53, p. 427-435, 1966. 